\title{
Mitral valve replacement with a transcatheter valve in the setting of severe mitral annular calcification
}

\author{
Raymond Lee, MD, Shinichi Fukuhara, MD, Isaac George, MD, and Michael A. Borger, MD, PhD,
} New York, NY

\footnotetext{
From the Division of Cardiac, Thoracic, and Vascular Surgery, Columbia University Medical Center, New York, NY.

Disclosures: M.A.B. receives speaker honoraria from Edwards Lifesciences. All other authors have nothing additional to disclose with regard to commercial support.

Received for publication Aug 11, 2015; revisions received Oct 5, 2015; accepted for publication Oct 18, 2015; available ahead of print Nov 19, 2015

Address for reprints: Michael A. Borger, MD, PhD, Department of Cardiac, Thoracic, and Vascular Surgery, Columbia University Medical Center, 177 Fort Washington Ave, MHB 7GN-435, New York, NY 10032 (E-mail: mb3851@cumc.columbia.edu).

J Thorac Cardiovasc Surg 2016;151:e47-9

$0022-5223 / \$ 36.00$

Copyright (C) 2016 Published by Elsevier Inc. on behalf of The American Association for Thoracic Surgery http://dx.doi.org/10.1016/j.jtcvs.2015.10.040
}

Mitral annular calcification (MAC) complicates mitral valve replacement surgery. Significant calcification makes débridement and placement of transannular sutures very difficult. Leaving the calcification undisturbed often results in an orifice opening that is too small to accommodate an adequately sized valve prosthesis. Extensive removal of MAC usually necessitates repair with an atrial sliding plasty or pericardial patch reconstruction, with subsequent risk of compromise to the circumflex coronary system, calcific embolism to end organs, or-most concerning-atrioventricular disruption with a high risk of mortality. ${ }^{1,2} \mathrm{We}$ describe a novel approach that uses a transcatheter Sapien XT valve (Edwards Lifesciences, Irvine, Calif) with a back-table improvised felt sewing cuff and 3 transannular sutures for anchoring.

\section{CLINICAL SUMMARY}

An 84-year-old, previously active woman was seen with a 3-month history of increasing shortness of breath (New York Heart Association functional class III-IV). The patient's symptoms worsened progressively, resulting in use of a wheelchair.

A transthoracic echocardiogram revealed severe aortic and mitral stenosis. The aortic mean gradient was $100 \mathrm{~mm} \mathrm{Hg}$ with a peak velocity of $6 \mathrm{~m} / \mathrm{s}$. Transesophageal echocardiography revealed severe MAC with severe mitral stenosis (mean gradient of $13 \mathrm{~mm} \mathrm{Hg}$; effective orifice area of $1.3 \mathrm{~cm}^{2}$ ). Left ventricular ejection fraction was $54 \%$, and right ventricular systolic pressure was markedly elevated at $82 \mathrm{~mm} \mathrm{Hg}$. Preoperative computed tomographic scan with calcium scoring confirmed extensive MAC with a severely narrowed mitral orifice $(17 \times 32 \mathrm{~mm}$; Figure 1$)$.

Preoperative heart catheterization showed nonobstructive coronary artery disease and severe reversible pulmonary hypertension. Because of the patient's advanced age and

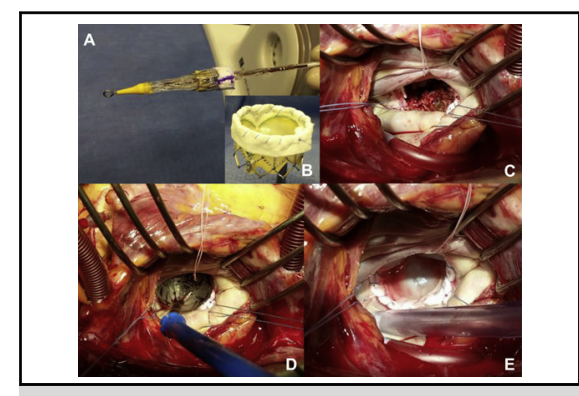

Fully deployed Sapien XT valve. Three annular sutures were sewn to the felt strip.

Central Message

We describe a novel technique that uses the $\mathrm{Sa}$ pien XT valve with an improvised sewing cuff for mitral valve replacement in severe MAC.

See Editorial Commentary page e49.

severe MAC, the patient was considered to be at high risk for conventional double valve replacement and therefore gave consent for aortic valve replacement with direct atrial deployment of a Sapien XT transcatheter valve.

Median sternotomy was performed, and cardiopulmonary bypass was achieved with standard central aortic and bicaval cannulation. The heart was arrested with antegrade cardioplegia. The severely calcified aortic valve was débrided and sized to fit a 21-mm Trifecta valve (St Jude Medical, Minneapolis, Minn). The mitral valve was exposed through the left atrium. Severe MAC was encountered, with a markedly reduced valvular orifice area that was unable to accommodate a 19-mm valve sizer (Perimount; Edwards Lifesciences). Both leaflets, along with parts of the subvalvular apparatus, were resected. Enough MAC was débrided so that the mitral orifice could then accommodate a 23-mm Perimount sizer. On the back table, a soft felt strip was secured to a 26-mm Sapien XT valve frame with a running 5-0 Prolene suture (Ethicon US, LLC, Somerville, $\mathrm{NJ}$ ), and the valve was subsequently crimped (Figure 2, $A$ and $B$ ). Three pledgeted 3-0 TiCron sutures (Medtronic Minimally Invasive Therapies, Minneapolis, Minn) were placed equidistant through the mitral annulus (Figure 2, $C)$. The Sapien valve was deployed into the mitral annulus under direct vision, with enough balloon inflation used to achieve adequate coaptation with the annulus (Figure 2, $D)$. The metal strut positions were inspected to avoid left ventricular outflow tract obstruction. The 3 anchoring 


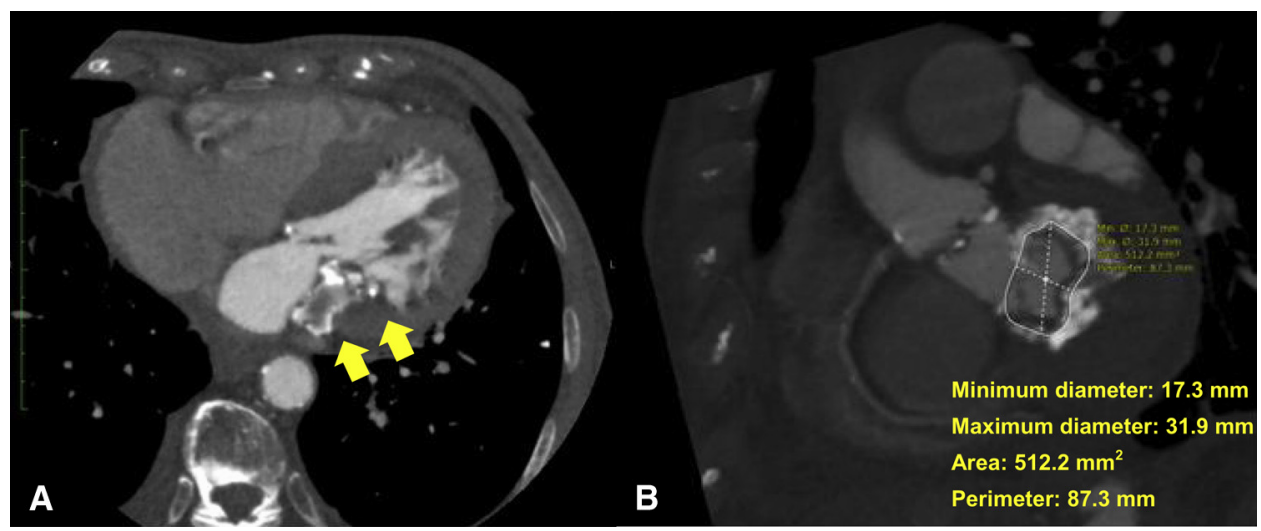

FIGURE 1. A, Computed tomography with calcium scoring, showing severe mitral annular calcification. B, Severe mitral annular calcification with markedly reduced valvular orifice area.

sutures were secured to the soft felt cuff and tied into place. The left atrium and left ventricle were thoroughly irrigated with saline solution, and the left atrium was closed. The aortic valve was replaced with a 21-mm Trifecta valve. Cardiopulmonary bypass time was 1 hour and 59 minutes, and crossclamp time was 1 hour and 51 minutes. Postbypass transesophageal echocardiography showed good aortic and mitral valvular function, with a mild mitral paravalvular leak along with preserved left ventricular function. Mean gradient across the aortic valve was $5 \mathrm{~mm} \mathrm{Hg}$ and a peak of $13 \mathrm{~mm} \mathrm{Hg}$ with no gradient across the left ventricular outflow tract.

The patient recovered well from surgery and was discharged on postoperative day 12. Predischarge transthoracic echocardiography revealed a mean mitral transvalvular gradient of $2 \mathrm{~mm} \mathrm{Hg}$ and resolution of the paravalvular jets. The patient was discharged on a regimen of low-dose aspirin for anticoagulation.

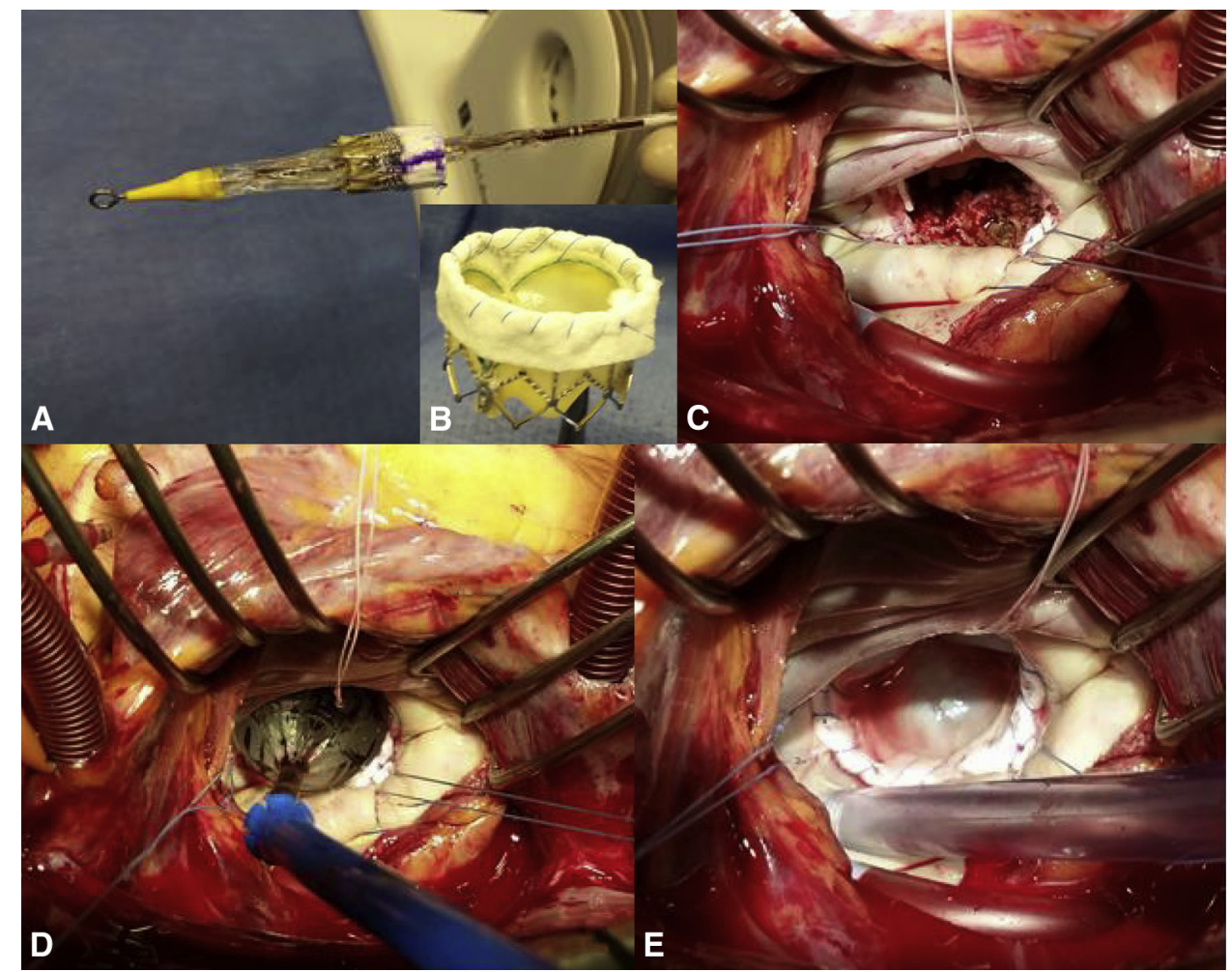

FIGURE 2. A, Crimped Sapien XT valve with modified felt cuff. B, Felt strip sewn directly to Sapien XT inflow surface. C, Subtotal débridement of calcium was performed, followed by placement of 3 equidistant annular sutures. D, Balloon expansion of 26-mm Sapien XT valve. E, Fully deployed valve being tested with saline injection. The 3 annular sutures were sewn to the felt strip and tied thereafter. 


\section{DISCUSSION}

MAC can pose a significant challenge for even the most experienced surgeons and multiple techniques have been proposed to address this challenging problem. Novel atrial sliding plasties, anterior leaflet transposition, and autologous or xenograft patch plasty have been reported. ${ }^{2,3}$ These extensive procedures require prolonged myocardial ischemic and cardiopulmonary bypass times, however, and they are associated with a not insignificant risk of circumflex artery injury, atrioventricular dissociation, and calcific embolization.

The patient had severe MAC with a severely narrowed mitral orifice, limiting surgical options. Because of the patient's advanced age, concomitant severe aortic stenosis, and MAC, we decided to perform a direct-vision deployment of a Sapien XT valve with an improvised sewing cuff to minimize paravalvular leak and prevent valve migration. This novel technique may serve as a useful treatment option for patients with severe MAC.

\section{References}

1. Izzat MB, Smith GH. Rupture of left ventricle after mitral valve repair: case report and new technique of repair. Br Heart J. 1993;69:366-7.

2. Carpentier AF, Pellerin M, Fuzellier JF, Relland JM. Extensive calcification of the mitral valve anulus: pathology and surgical management. J Thoracic Cardiovasc Surg. 1996;111:718-29; discussion 729-30.

3. Feindel CM, Tufail Z, David TE, Ivanov J, Armstrong S. Mitral valve surgery in patients with extensive calcification of the mitral annulus. J Thoracic Cardiovasc Surg. 2003;126:777-82.

\title{
EDITORIAL COMMENTARY
}

\section{A very elegant transcatheter strategy for complicated mitral valve replacement associated with severe mitral annular calcification}

\author{
Jessica Forcillo, MD, MSc, FRCSC, ${ }^{\mathrm{a}}$ Vasilis Babaliaros, MD, ${ }^{\mathrm{b}}$ and Vinod H. Thourani, MD
}

\footnotetext{
From the ${ }^{\mathrm{a}}$ Division of Cardiothoracic Surgery, Joseph B. Whitehead Department of Surgery, and ${ }^{\mathrm{b}}$ Division of Cardiology, Department of Medicine, Structural Heart and Valve Center, Emory University School of Medicine, Atlanta, Ga.

Disclosures: Drs Babaliaros and Thourani are members of the Edwards Lifesciences Advisory Board and have conducted paid research for Edwards Lifesciences. The other author has nothing to disclose with regard to commercial support.

Received for publication Nov 2, 2015; accepted for publication Nov 4, 2015; available ahead of print Dec 11, 2015.

Address for reprints: Vinod H. Thourani, MD, Emory University Hospital Midtown, 550 Peachtree St, NE, 6th Fl Medical Office Tower, Atlanta, GA 30308 (E-mail: vthoura@emory.edu).

J Thorac Cardiovasc Surg 2016;151:e49-50

0022-5223/\$36.00

Copyright (c) 2016 by The American Association for Thoracic Surgery

http://dx.doi.org/10.1016/j.jtcvs.2015.11.005
}

Mitral annular calcification (MAC) is a chronic and degenerative process of the mitral annulus that could lead to fatal outcomes in the context of mitral valve replacement during cardiac surgery due to atrioventricular disruption, circumflex artery injury, and calcific embolization. ${ }^{1,2}$ The reported prevalence of $\mathrm{MAC}$ in the general surgical population is between $8 \%$ and $15 \%$, but it can significantly increase with age. ${ }^{3}$ A study done by Gondrie and colleagues ${ }^{4}$ showed the association between incidentally detected mitral valve calcifications and future cardiovascular events. They found that mitral valve leaflet calcification and MAC had an odds ratio 2.08 and 1.53 increased risk, respectively, of experiencing an event during the perioperative period. $^{4}$ Several techniques for the intraoperative management of MAC have been described in the literature,

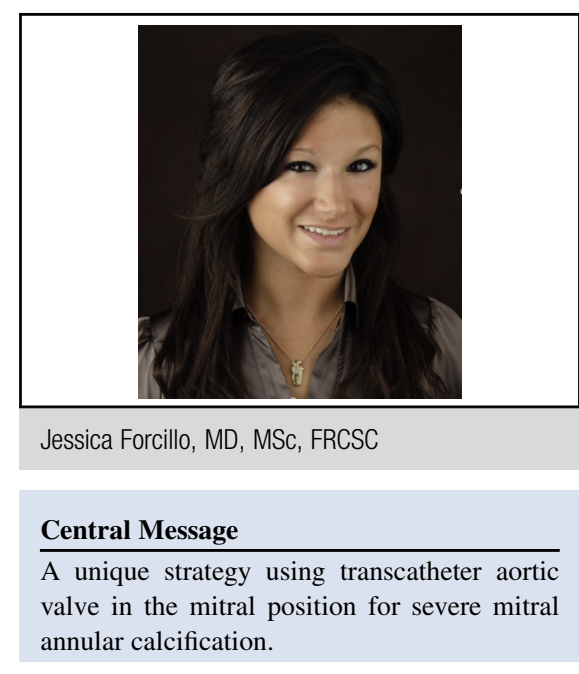

See Article page e47.

ranging from careful incomplete debridement of the annulus, atrial sliding plasty, anterior leaflet transposition, implantation of the mitral valve on a polytetrafluoroethylene or polyethylene terephthalate felt protruding into the left atrium, to complete debridement MAC with atrioventicular patch repair followed by valve replacement. Some have also published reports on implantation of the mitral valve inside the atrium and sutured around the pulmonary veins. 5,6 